\title{
Effects of rumen-protected Capsicum oleoresin on immune responses in dairy cows intravenously challenged with lipopolysaccharide
}

\author{
J. Oh, ${ }^{*}$ M. Harper, ${ }^{*}$ F. Giallongo, ${ }^{*}$ D. M. Bravo, † E. H. Wall, $†$ and A. N. Hristov*1 \\ *Department of Animal Science, The Pennsylvania State University, University Park 16802 \\ †Pancosma S.A., CH-1218, Geneva, Switzerland
}

\begin{abstract}
The objective of this experiment was to investigate the effects of rumen-protected Capsicum oleoresin (RPC) on productivity and immune responses including feed intake, milk yield and composition, white and red blood cells, lipid peroxidation, and blood concentration of cortisol, haptoglobin, glucose, and insulin in lactating dairy cows experimentally challenged with lipopolysaccharide (LPS). The experiment was a replicated $3 \times 3$ Latin square design with 9 multiparous Holstein cows in three 28-d periods. Treatments were 0 (control), 100, and 200 $\mathrm{mg}$ of RPC/cow per day, mixed with small portions of the total mixed ration and top-dressed. Bacterial LPS was intravenously administered at $1.0 \mu \mathrm{g} / \mathrm{kg}$ of body weight in the last week of each experimental period, and blood samples were collected at $0,2,4,8$, and $24 \mathrm{~h}$ after administration. Dry matter intake, milk yield, and white blood cells including neutrophils, lymphocytes, monocytes, and eosinophils were decreased, and rectal temperature, hemoglobin, and serum concentrations of cortisol and haptoglobin were increased by LPS. Red blood cells, platelets, and plasma concentration of thiobarbituric acid reactive substances were not affected by LPS. Dry matter intake, milk yield, and milk composition in the $5 \mathrm{~d}$ post-LPS challenge were not affected by RPC. Rectal temperature, white blood cells, red blood cells, hemoglobin, and platelets were also not affected by RPC. Compared with the control, RPC tended to decrease cortisol at $2 \mathrm{~h}$ following LPS challenge and decreased haptoglobin concentration in serum across sampling points. Concentration of thiobarbituric acid reactive substances in plasma was decreased by RPC at $24 \mathrm{~h}$ post-LPS challenge. Glucose and insulin were not affected by RPC, but serum insulin concentration at 8 $\mathrm{h}$ was lowered by RPC compared to the control. Col-
\end{abstract}

Received June 26, 2016.

Accepted November 18, 2016.

${ }^{1}$ Corresponding author: anh13@psu.edu lectively, RPC had no or subtle effects on feed intake, milk yield and composition, rectal temperature, white and red blood cells, and serum glucose and insulin concentration in dairy cows challenged by LPS. However, RPC tended to decrease cortisol and decreased concentrations of haptoglobin and thiobarbituric acid reactive substances in blood following LPS challenge. Data suggest that dietary supplementation of RPC may modulate acute phase responses induced by bacterial infection in lactating dairy cows.

Key words: Capsicum oleoresin, lipopolysaccharide, acute phase response, dairy cow

\section{INTRODUCTION}

Cows experience acute phase responses at the onset of bacterial infection as other animal species do (Cray et al., 2009). These responses are natural innate reactions to the external invasion and include increased body temperature, recruitment of leukocytes to the sites of infection, and production of inflammatory cytokines, reactive oxygen species, cortisol, and acute phase proteins (Gruys et al., 2005). Ideally, acute phase responses help the immune system initially protect the body and then develop adaptive immunity (Hoebe et al., 2004). During an infection, the immune system of the dairy cow consumes energy and nutrients, which decreases milk synthesis (Bradford et al., 2015). In addition, reactive oxygen species released from neutrophils may damage epithelial tissue in the mammary gland in case of mammary infection, which reduces milk synthesis and secretion (Sordillo and Aitken, 2009). Bradford et al. (2015) indicated that delayed resolution of inflammation may cause metabolic disease, infertility, and impaired milk production. Thus, anti-inflammatory treatments may be beneficial for recovery of homeostasis and productivity in dairy cows.

Capsaicin (8-methyl- $N$-vanillyl-trans-6-nonenamide) is a major pungent ingredient in Capsicum fruits that are widely used as spices. Capsaicin is known to have regulatory effects on immune cells including macrophages, neutrophils, $\mathrm{T}$ lymphocytes, and B lympho- 
cytes in studies in vivo and in vitro (Nilsson et al., 1991; Takano et al., 2007; Franco-Penteado et al., 2006; Nevius et al., 2012). Capsaicin exerts regulatory effects by binding to a capsaicin receptor, transient receptor potential cation channel subfamily $\mathrm{V}$ member 1 (TRPV1), which is widely expressed on sensory neurons, intestines, brain, kidneys, liver, and bladder as well as on polymorphonuclear granulocytes, mast cells, and macrophages (Reyes-Escogido et al., 2011). Capsaicin directly acts on the cells through TRPV1 on the cell surface or indirectly affects them by stimulating the afferent neurons to release neuropeptides such as calcitonin gene-related peptide and substance P (Cortright and Szallasi, 2004; Tsuji and Aono, 2012). These neuropeptides are known to modulate anti- or proinflammatory responses (Bender and Granstein, 2009).

The effects of Capsicum oleoresin, an acetone or hexane extract from Capsicum fruits, on immune responses have been investigated in pigs, chicken, and cattle (Wesolowska et al., 2011; Lee et al., 2013; Oh et al., 2013; Liu et al., 2014). Capsicum oleoresin exhibited anti-inflammatory effects in pigs challenged with Escherichia coli by decreasing acute phase immune responses such as increased haptoglobin concentration and neutrophil counts in blood (Liu et al., 2013a). Capsicum oleoresin paired with turmeric oleoresin decreased gut lesion scores and inflammatory cytokines and increased BW in chickens with necrotic enteritis (Lee et al., 2013). With respect to dairy cows, a pulse dose of Capsicum oleoresin into the abomasum increased proportions of lymphocyte and $\mathrm{CD}^{+} \mathrm{T}$ cells (Oh et al., 2013). Dietary supplementation of a granular form of Capsicum oleoresin increased neutrophils and monocytes in peripheral blood (Oh et al., 2015). In both studies with dairy cows, Capsicum oleoresin exhibited the pro-inflammatory effects without an immune challenge. Responses, however, could be different if cows were immunologically challenged. Indeed, Capsicum oleoresin exhibited anti-inflammatory effects in porcine macrophages challenged with LPS, whereas pro-inflammatory effects were observed in the cells with no challenge (Liu et al., 2012).

Therefore, we hypothesized that Capsicum oleoresin may act postruminally in the digestive tract and may decrease the intensity of immune responses induced by LPS in dairy cows. The objective of the current study was to investigate the effects of rumen-protected Capsicum oleoresin (RPC) supplementation on productivity and immune responses including feed intake, milk yield and composition, white and red blood cells, lipid peroxidation, and blood concentration of cortisol, haptoglobin, glucose, and insulin in lactating dairy cows experimentally challenged with LPS.

\section{MATERIALS AND METHODS}

\section{Animals and Treatments}

This study was part of a larger experiment reported in our companion paper (Oh et al., 2017). All procedures in this study were approved by The Pennsylvania State University Animal Care and Use committee. The experiment was a replicated $3 \times 3$ Latin square design balanced for residual effects and was conducted at the tie-stall barn of The Pennsylvania State University's Dairy Teaching and Research Center with 9 Holstein cows (milk yield, $47 \pm 5.7 \mathrm{~kg}$; DIM, $100 \pm 9.1$ $\mathrm{d}$; and BW, $665 \pm 83.3 \mathrm{~kg}$, at the beginning of the experiment). Cows were grouped in squares by age and milk yield and consumed a basal TMR ad libitum that was delivered once daily at around $0800 \mathrm{~h}$, targeting 5 to $10 \%$ refusals. During the time of feeding, RPC was mixed with about $500 \mathrm{~g}$ of TMR and top-dressed. Three treatments were tested in this experiment: 0 $\mathrm{mg} / \mathrm{d}$ of RPC (control), $100 \mathrm{mg} / \mathrm{d}$ of RPC (C100), and $200 \mathrm{mg} / \mathrm{d}$ of RPC (C200). The RPC product used in the experiment was Nexulin (X50-7035; 15.5\% Capsicum oleoresin; 0.93\% capsaicinoids; Pancosma, S. A., Geneva, Switzerland). The dose amount was determined based on our previous study with lactating dairy cows (Oh et al., 2015). Each experimental period of the main study lasted $28 \mathrm{~d}$, including 14 $\mathrm{d}$ for adaptation and $14 \mathrm{~d}$ for data collection and sampling. Ingredients and chemical composition of the basal diet are reported in the companion paper (Oh et al., 2017). Briefly, the diet consisted of (DM basis): $44 \%$ corn silage, $12 \%$ alfalfa haylage, and $41 \%$ concentrate feeds and contained $16.1 \% \mathrm{CP}$ and $30.9 \%$ NDF. The diet met the $\mathrm{NE}_{\mathrm{L}}$ and $\mathrm{MP}$ requirements of the cows according to NRC (2001). Recombinant bST (500 mg, i.m., Posilac; Elanco Co., Greenfield, IN) was administered at the beginning and middle of each experimental period.

\section{Sampling and Analyses}

Intake, refusal weights, and milk production were recorded daily, and data before the LPS challenge are reported in the companion paper (Oh et al., 2017).

On d 22 of each experimental period, catheters (14-gauge $\times 13 \mathrm{~cm}$; MILA International Inc., Erlanger, $\mathrm{KY}$ ) were installed in the jugular vein and flushed with heparinized saline $(10 \mathrm{IU} / \mathrm{mL})$. Immune challenges were conducted once during the last week of each experimental period with bacterial LPS (Escherichia coli O111:B4; Sigma Chemical Co., St. Louis, MO) through jugular vein infusion. On the day of the infusion, LPS 
$(1.0 \mu \mathrm{g} / \mathrm{kg}$ of BW) was dissolved in $100 \mathrm{~mL}$ of $0.9 \%$ sterile saline. The LPS solution was infused into the jugular vein of all cows at a rate of $1 \mathrm{~mL} / \mathrm{min}$ through sterile tubing by 2 peristaltic pumps (Masterflex L/S, Cole-Parmer Instrument, Vernon Hills, IL) for $100 \mathrm{~min}$. The infusion began at feeding time and blood samples were collected at $0,2,4,8$, and $24 \mathrm{~h}$ after the end of the infusion. The first set of samples (approximately $10 \mathrm{~mL}$ ) was collected into vacuumed tubes containing EDTA (BD Biosciences, Franklin Lakes, NJ), kept refrigerated at $4^{\circ} \mathrm{C}$, and analyzed on the same or next day for hematology including counts for total white blood cells, neutrophils, eosinophils, lymphocytes, monocytes, basophils, red blood cell, and platelet and hemoglobin concentration using an automated hematology analyzer (HemaVet; Drew Scientific, Oxford, CT). Another set of blood samples were collected from the catheters into vacuumed tubes (SST Tube; BD Biosciences) for blood serum analysis and allowed to clot at room temperature. Blood serum was obtained by centrifugation at $3,000 \times g$ at room temperature for $15 \mathrm{~min}$ and kept frozen at $-80^{\circ} \mathrm{C}$ until analysis for cortisol, haptoglobin, glucose, and insulin. Serum cortisol concentration was analyzed by a radioimmunoassay kit (ImmuChem Coated Tube; MP Biomedicals, Orangeburg, NY). Inter- and intra-assay precision of the cortisol kit was 7.6 to $9.3 \% \mathrm{CV}$ and 5.3 to $8.9 \% \mathrm{CV}$, respectively. The minimum detection level of cortisol was $0.17 \mu \mathrm{g} / \mathrm{dL}$. A biochemistry analyzer (Cobas 6000; Roche, Germany) was used for haptoglobin concentration analysis. Blood glucose concentration was analyzed using a colorimetric assay (Glucose LiquiColor, Stanbio, Boerne, TX). Glucose oxidase was used in this kit to produce hydrogen peroxide, which forms color with phenol. Inter- and intra-assay precision of the glucose kit was 1.2 to $1.6 \%$ $\mathrm{CV}$ and 2.0 to $3.0 \% \mathrm{CV}$, respectively. Insulin was analyzed using a radioimmunoassay kit (PI-12K, EMD Millipore, Billerica, MA). According to the manufacturer's manual, the specificity for bovine insulin in the assay kit was $90 \%$. Recovery tests were conducted to correct the underestimation of insulin concentration, and the minimum detection level in the kit was $1.611 \mu \mathrm{U} / \mathrm{mL}$. A third set of blood samples were collected into vacuumed tubes containing EDTA (BD Biosciences). Plasma was obtained by centrifugation at $1,500 \times g$ at $4^{\circ} \mathrm{C}$ for 10 min, stored frozen at $-80^{\circ} \mathrm{C}$, and analyzed for thiobarbituric acid reactive substances (TBARS) using a colorimetric assay (Cayman Chemical, Ann Arbor, MI). Inter- and intra-assay precision of the TBARS kit was 5.1 to $5.9 \% \mathrm{CV}$ and 5.5 to $7.6 \% \mathrm{CV}$, respectively, and the assay range was 0 to $50 \mu M$. Rectal temperature of the cows was measured at the time of blood sampling by a thermometer (Mabis Select Accurate LCD Digital Thermometer; Mabis, Waukegan, IL).

Samples for milk composition were collected on the day after the LPS challenge (afternoon/evening and morning milkings) and submitted to Dairy One laboratory (Pennsylvania DHIA, University Park, PA) for analysis of fat, protein, lactose, SCC, and MUN (MilkoScan 4000; Foss Electric, Hillerød, Denmark). Milk composition data were weighted for the corresponding afternoon/evening and morning milk yields. Aliquots of the milk samples were analyzed for capsaicin using a triple quadrupole mass spectrometry (Waters Xevo; Waters Corporation, Milford, MA). Milk samples $(0.5 \mathrm{~mL})$ were mixed with methanol $(1.0$ $\mathrm{mL}$ ) to extract capsaicin and analyzed with $1 \mathrm{~m} M$ of chlorpropamide solution as an internal standard. The samples were mixed by vortexing for 2 min and were then centrifuged at $20,000 \times g$ for $10 \mathrm{~min}$. Supernatant $(0.5 \mathrm{~mL})$ was collected into 2 -mL mass-spectrometer autosampler vials. Samples $(5 \mu \mathrm{L})$ were separated by reverse phase HPLC using an Acquity H-class ultraperformance liquid chromatography system with a BEH C18 column $(100 \mathrm{~mm} \times 2.1 \mathrm{~mm}, 1.7-\mu \mathrm{m}$ particle size; Waters Corporation) maintained at $55^{\circ} \mathrm{C}$ and a 20 min aqueous acetonitrile gradient, at a flow rate of 250 $\mu \mathrm{L} / \mathrm{min}$. Solvent A was HPLC grade water with $0.1 \%$ formic acid, and Solvent B was HPLC grade acetonitrile with $0.1 \%$ formic acid. The initial conditions were $97 \%$ solvent A and $3 \%$ solvent B, increasing to $45 \%$ solvent $\mathrm{B}$ at $10 \mathrm{~min}$ and $75 \%$ solvent $\mathrm{B}$ at $12 \mathrm{~min}$, which was held until $17.5 \mathrm{~min}$, before returning to the initial conditions. The eluate was delivered into a Xevo TQS triple quadrupole mass spectrometer (Waters Corporation) operated in positive ion mode. Quantification was performed with multiple reaction monitoring and the transitions of mass to charge values were 306.2 to 137.2 for capsaicin and 277.0 to 175.1 for the internal standard. In addition, TBARS concentration in milk was analyzed as previously described for plasma.

\section{Statistical Analysis}

All data were analyzed using the MIXED procedure of SAS software (version 9.3, 2003; SAS Institute Inc., Cary, NC). Milk yield, DMI, and estimated feed efficiency data for $5 \mathrm{~d}$ following the LPS challenge during each experimental period were used in the statistical analysis. Averaged milk yield, DMI, and milk composition data were used to calculate yields of milk fat, protein, lactose, and ECM. Data were processed for outlier identification based on an absolute studentized residual values $>3$ using the REG procedure of SAS. Normal- 
ity of the data was assessed using the UNIVARIATE procedure of SAS. When the $W$ statistic of the ShapiroWilk test was $<0.05$, data were log-transformed for the statistical analysis.

Composition and TBARS concentration in milk and data for individual sampling time point post LPS challenge for rectal temperature, blood cell counts, and blood concentrations of TBARS, cortisol, haptoglobin, glucose, and insulin were analyzed by ANOVA Latin square. The model used was as follows:

$$
Y_{i j k l}=\mu+\mathrm{S}_{i}+\mathrm{C}(\mathrm{S})_{i j}+\mathrm{P}_{k}+\mathrm{T}_{l}+\mathrm{PT}_{k l}+\mathrm{e}_{i j k l},
$$

where $Y_{i j k l}$ is the dependent variable, $\mu$ is the overall mean, $\mathrm{S}_{i}$ is the square, $\mathrm{C}(\mathrm{S})_{i j}$ is the cow within square, $\mathrm{P}_{k}$ is the $k$ th period, $\mathrm{T}_{l}$ is the lth treatment, and $\mathrm{PT}_{k l}$ is the period $\times$ treatment effect with the error term $\mathrm{e}_{i j k l}$. Square and cow within square were random effects and all others were fixed.

Dry matter intake, milk yield, and feed efficiency and rectal temperature, blood cell counts, and serum or plasma concentrations of TBARS, cortisol, haptoglobin, glucose, and insulin for all the sampling time points post LPS challenge were analyzed as repeated measures assuming an AR(1) covariance structure. The model used was

$$
\begin{aligned}
Y_{i j k l m}= & \mu+\mathrm{S}_{i}+\mathrm{C}(\mathrm{S})_{i j}+\mathrm{P}_{k}+\mathrm{T}_{l}+\mathrm{D}_{m} \\
& +\mathrm{PT}_{k l}+\mathrm{TD}_{l m}+\mathrm{e}_{i j k l m},
\end{aligned}
$$

where $Y_{i j k l m}$ is the dependent variable, $\mu$ is the overall mean, $\mathrm{S}_{i}$ is the square, $\mathrm{C}(\mathrm{S})_{i j}$ is the cow within square, $\mathrm{P}_{k}$ is the $k$ th period, $\mathrm{T}_{l}$ is the $l$ th treatment, $\mathrm{D}_{m}$ is the time effect, $\mathrm{PT}_{k l}$ is the period $\times$ treatment interaction, and $\mathrm{TD}_{l m}$ is the treatment $\times$ time interaction with the error term $\mathrm{e}_{i j k \mathrm{~km}}$. Square and cow within square were random effects and all others were fixed.

Orthogonal contrasts were used to evaluate the overall effect of RPC versus control and linear effects of RPC supplementation. Statistical differences were considered significant at $P \leq 0.05$ and a trend at 0.05 $<P \leq 0.10$.

\section{RESULTS}

The LPS challenge decreased $(P<0.01)$ DMI and milk yield by an average of 3.87 and $8.07 \mathrm{~kg} / \mathrm{d}$, respectively, compared with the prechallenge data (Oh et al., 2017). Dry matter intake for all cows immediately dropped the day after the LPS challenge and recovered within $2 \mathrm{~d}$ (Figure 1). Milk yield was also decreased by the immune challenge and reached the lowest levels on
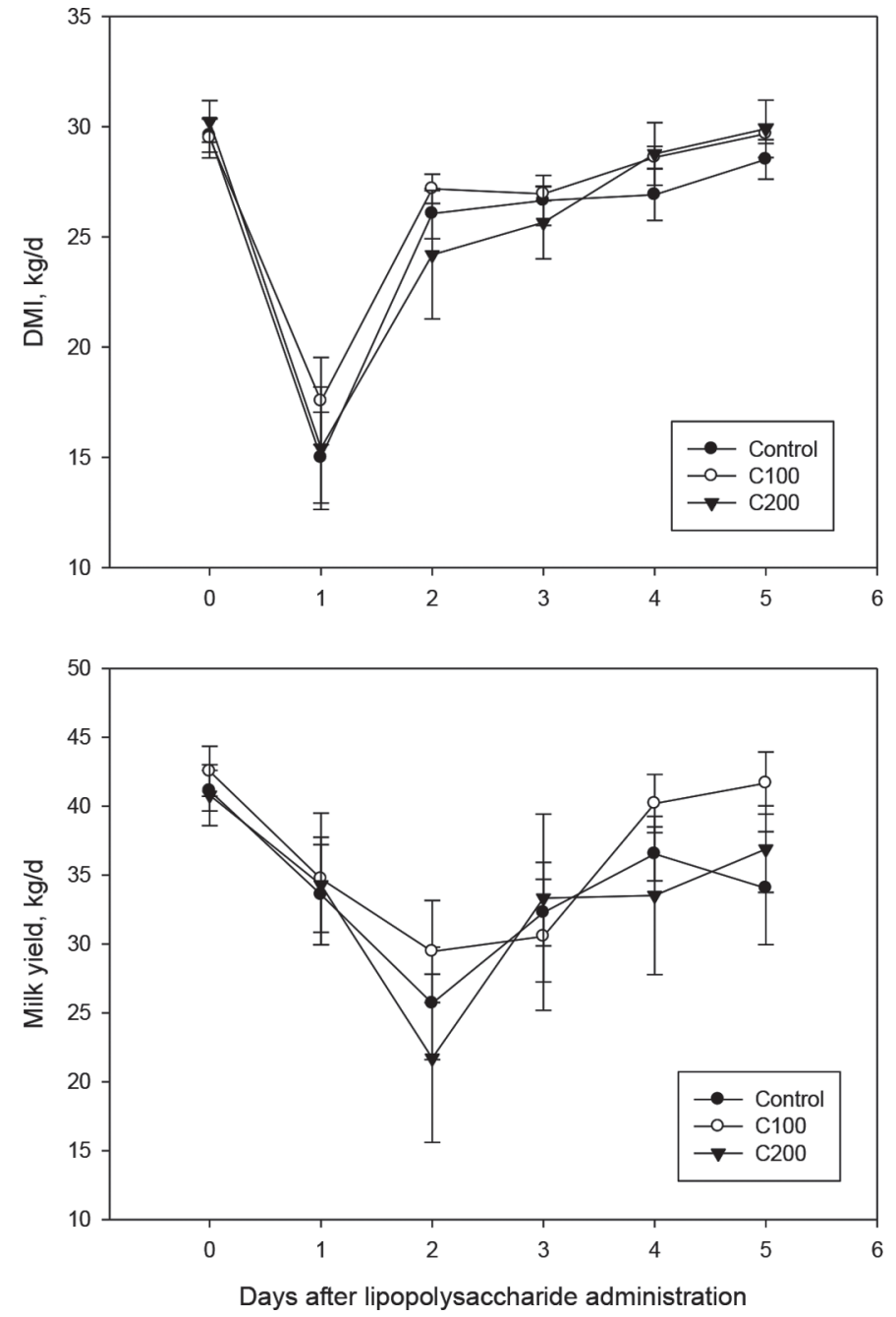

Figure 1. Effect of rumen-protected Capsicum oleoresin (RPC) on DMI and milk yield of dairy cows post-LPS challenge. Control $=0$ $\mathrm{mg} / \mathrm{d}$ of RPC; C100 $=100 \mathrm{mg} / \mathrm{d}$ of RPC; C200 $=200 \mathrm{mg} / \mathrm{d}$ of RPC. Error bars represent SE $(\mathrm{n}=23$; $\mathrm{n}$ represents number of observations used in the statistical analysis).

d 2 post LPS challenge. Compared with the control, $\mathrm{RPC}$ had no effect on the extent of reduction in DMI and milk yield induced by LPS challenge (Table 1). Milk composition including fat, true protein, lactose, MUN, and SCC in milk was similar among treatments. Capsaicin was not found in milk; the detection limit of the analytical procedure used in the current experiment was $200 \mathrm{pg} / \mathrm{mL}$. Milk TBARS concentration was also not affected by RPC (Table 1 ).

Rectal temperature peaked at $2 \mathrm{~h}$ post-LPS challenge for the control and C100 cows and at $4 \mathrm{~h}$ for C200 cows, and returned to the basal temperature for all treatments at $8 \mathrm{~h}$ (data not shown). We observed no effect of $\mathrm{RPC}$ on rectal temperature at individual measurement 
times or when rectal temperature data were analyzed as repeated measures.

White blood cell counts, including neutrophils, lymphocytes, monocytes, and eosinophils, immediately decreased in all treatments and reached a nadir at 2 $\mathrm{h}$ after LPS challenge (data not shown). Cows experienced leukopenia by the immune challenge in the current experiment. The normal ranges of white blood cell counts in dairy cows are 4,000 to $12,000,600$ to 4,100 , 2,500 to $7,500,0$ to 1,200 , and 0 to 2,400 per microliter for total white blood cells, neutrophils, lymphocytes, monocytes, and eosinophils, respectively (Kramer, 2000). Total white blood cells and neutrophils increased $(P<0.01)$ at $24 \mathrm{~h}$ post-LPS challenge, compared to prechallenge. Lymphocytes and monocytes recovered to the levels of pre-LPS status at $24 \mathrm{~h}$, while neutrophil and eosinophil counts recovered at $8 \mathrm{~h}$. Overall, RPC did not affect white blood cells following LPS challenge, although lymphocyte counts were increased $(P$ $=0.02)$ at $0 \mathrm{~h}$ for RPC supplementation compared to the control. We also found no effect of RPC on white blood cells when data were analyzed as repeated measures (Table 2). Red blood cells and platelets were not affected by LPS, whereas hemoglobin increased $(P<$ $0.05)$ at $8 \mathrm{~h}$ after the LPS challenge compared to $0 \mathrm{~h}$ (data not shown). The RPC supplementation did not affect red blood cells, platelets, or hemoglobin (Table 2).

Serum cortisol concentration peaked at $2 \mathrm{~h}$ post LPS challenge for all treatments and returned to basal levels at $8 \mathrm{~h}$ (Figure 2). Cortisol concentration tended to be lower $(P=0.06)$ at $2 \mathrm{~h}$ for the RPC treatments compared to the control. Averaged across sampling points, RPC did not affect serum cortisol concentration $(P=$ 0.15 ; Table 3).

The immune challenge increased $(P<0.01)$ serum haptoglobin concentration at $24 \mathrm{~h}$ compared to pre-LPS status (Figure 3). Supplementation with RPC tended to decrease $(P=0.10)$ haptoglobin concentration at 24 $\mathrm{h}$ post-LPS challenge. Also, RPC decreased $(P=0.04)$ haptoglobin concentration compared to the control across sampling points post-LPS challenge (Table 3 ).

The LPS challenge did not affect plasma TBARS concentration until $24 \mathrm{~h}$ after the challenge in the current experiment (Figure 4). No effect of RPC on TBARS concentration was observed at 0,2 , and $8 \mathrm{~h}$ post-LPS challenge, but a trend $(P=0.06)$ for linear increase by RPC was observed at $4 \mathrm{~h}$. Concentration of TBARS was decreased $(P=0.02)$ by RPC at $24 \mathrm{~h}$ compared with the control. Across all sampling points

Table 1. Effect of rumen-protected Capsicum oleoresin (RPC) on feed intake and milk production and composition in dairy cows following LPS challenge ${ }^{1}$

\begin{tabular}{|c|c|c|c|c|c|c|}
\hline Item & \multicolumn{3}{|c|}{ Treatment $^{2}$} & $\mathrm{SEM}^{3}$ & \multicolumn{2}{|c|}{$P$-value ${ }^{4}$} \\
\hline DMI, $\mathrm{kg} / \mathrm{d}$ & 25.3 & 26.2 & 25.5 & 1.73 & 0.77 & 0.92 \\
\hline Feed efficiency, ${ }^{5} \mathrm{~kg} / \mathrm{kg}$ & 1.44 & 1.47 & 1.56 & 0.127 & 0.60 & 0.45 \\
\hline Milk fat, $\%$ & 3.97 & 3.68 & 3.91 & 0.253 & 0.25 & 0.72 \\
\hline Fat yield, kg/d & 1.11 & 1.06 & 1.08 & 0.158 & 0.81 & 0.88 \\
\hline Lactose yield, $\mathrm{kg} / \mathrm{d}$ & 1.27 & 1.28 & 1.31 & 0.196 & 0.93 & 0.90 \\
\hline $\mathrm{ECM},{ }^{6} \mathrm{~kg} / \mathrm{d}$ & 27.8 & 26.8 & 27.3 & 3.57 & 0.85 & 0.91 \\
\hline ECM feed efficiency, ${ }^{7} \mathrm{~kg} / \mathrm{kg}$ & 1.81 & 1.57 & 1.78 & 0.241 & 0.71 & 0.96 \\
\hline $\mathrm{TS}, \%$ & 12.7 & 12.4 & 12.5 & 0.54 & 0.57 & 0.71 \\
\hline MUN, mg/100 mL & 11.6 & 12.2 & 12.2 & 1.12 & 0.65 & 0.70 \\
\hline $\mathrm{SCC}, \times 10^{3}$ cells $/ \mathrm{mL}$ & 87.4 & 67.5 & 116 & 52.96 & 0.94 & 0.65 \\
\hline
\end{tabular}

${ }^{1}$ Data for DMI, milk yield, and feed efficiency were collected for $5 \mathrm{~d}$ after lipopolysaccharide challenge. Yield of milk components and ECM were calculated with milk yield for the day of milk sampling.

${ }^{2}$ Control $=0 \mathrm{mg} / \mathrm{d}$ of RPC; $100=100 \mathrm{mg} / \mathrm{d}$ of RPC; $200=200 \mathrm{mg} / \mathrm{d}$ of RPC.

${ }^{3}$ Highest SEM shown; $\mathrm{n}=114$ for DMI; $\mathrm{n}=109$ for milk yield, feed efficiency, and TBARS; $\mathrm{n}=21$ for all other variables ( $\mathrm{n}$ represents number of observations used in the statistical analysis).

${ }^{4}$ Con vs. RPC $=$ control vs. RPC treatment; Linear $=$ linear effect of RPC.

${ }^{5}$ Milk yield $\div$ DMI.

${ }^{6}$ Energy-corrected milk $(\mathrm{kg} / \mathrm{d})=\mathrm{kg}$ of milk $\times[(38.3 \times \%$ fat $\times 10+24.2 \times \%$ true protein $\times 10+16.54 \times \%$ lactose $\times 10+20.7) \div 3,140]$ (Sjaunja et al., 1990). ECM was calculated.

${ }^{7} \mathrm{ECM} \div$ DMI.

${ }^{8}$ TBARS $=$ thiobarbituric acid reactive substances. 


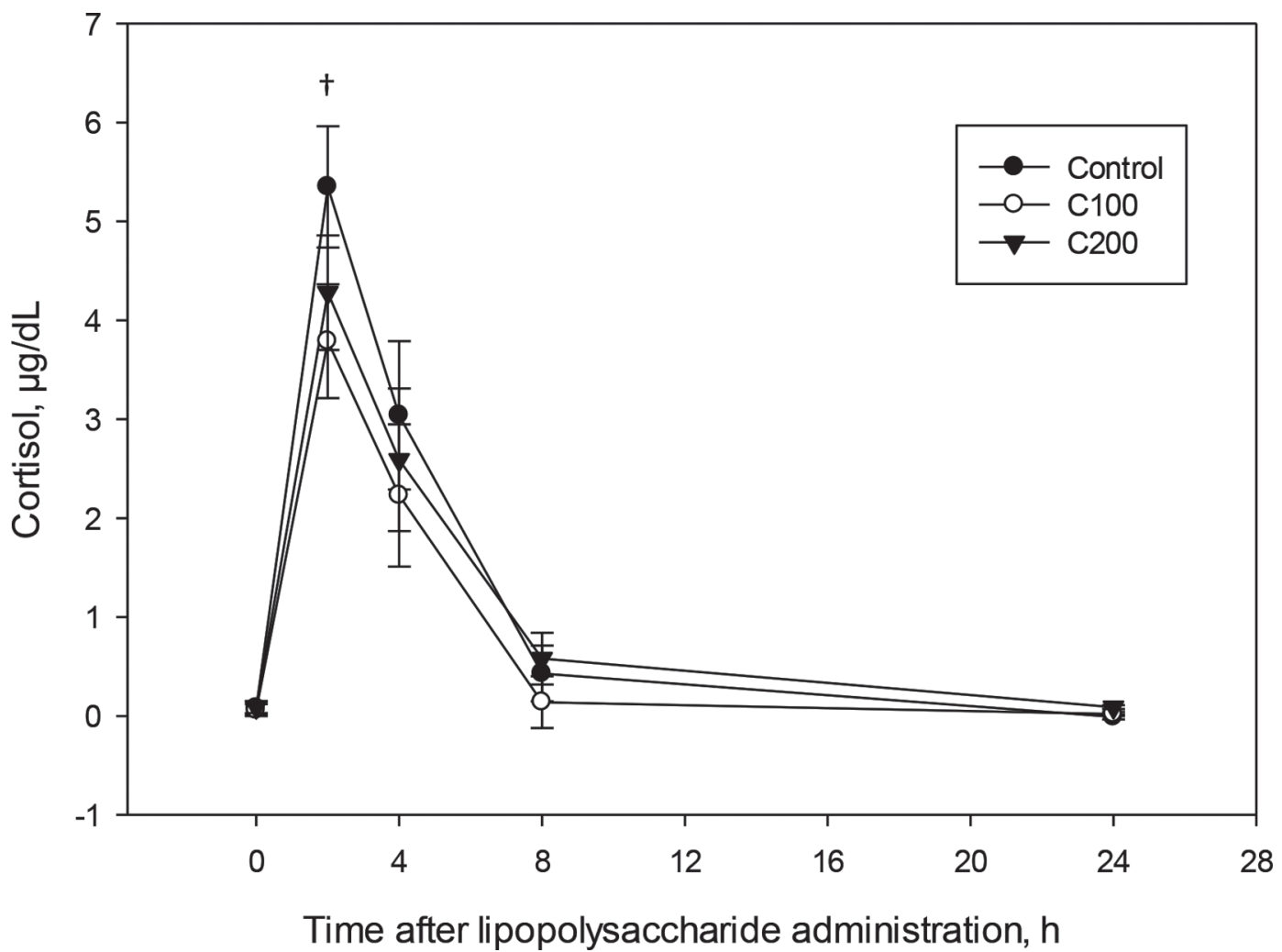

Figure 2. Effect of rumen-protected Capsicum oleoresin (RPC) on serum cortisol concentration at 0, 2, 4, 8, and 24 h after intravenous administration of LPS. Control $=0 \mathrm{mg} / \mathrm{d}$ of RPC; $\mathrm{C} 100=100 \mathrm{mg} / \mathrm{d}$ of RPC; $200=200 \mathrm{mg} / \mathrm{d}$ of RPC. $\dagger P=0.06 \mathrm{in}$ control vs. RPC. Time effect, $P<0.01$. Error bars represent SE (n $=23 ; \mathrm{n}$ represents number of observations used in the statistical analysis).

Table 2. Effect of rumen-protected Capsicum oleoresin (RPC) on blood cell counts in dairy cows following lipopolysaccharide challenge

\begin{tabular}{|c|c|c|c|c|c|c|}
\hline Item & \multicolumn{3}{|c|}{ Treatment $^{1}$} & $\mathrm{SEM}^{2}$ & \multicolumn{2}{|c|}{$P$-value ${ }^{3}$} \\
\hline White blood cells, $10^{3} / \mu \mathrm{L}$ & 5.68 & 5.55 & 5.23 & 0.503 & 0.61 & 0.48 \\
\hline Lymphocytes & 1.93 & 2.19 & 2.14 & 0.309 & 0.21 & 0.31 \\
\hline Monocytes & 0.14 & 0.12 & 0.12 & 0.036 & 0.72 & 0.71 \\
\hline Eosinophils & 0.29 & 0.23 & 0.21 & 0.060 & 0.20 & 0.18 \\
\hline Neutrophils & 47.8 & 45.4 & 44.5 & 4.11 & 0.37 & 0.35 \\
\hline Lymphocytes & 43.6 & 46.7 & 47.8 & 4.82 & 0.32 & 0.31 \\
\hline Monocytes & 2.47 & 2.31 & 2.68 & 0.380 & 0.95 & 0.69 \\
\hline Eosinophils & 5.58 & 5.23 & 4.61 & 1.158 & 0.53 & 0.43 \\
\hline Basophils & 0.51 & 0.40 & 0.38 & 0.131 & 0.34 & 0.36 \\
\hline Neutrophils:lymphocytes & 1.68 & 1.54 & 1.35 & 0.380 & 0.46 & 0.37 \\
\hline Red blood cells, $10^{6} / \mu \mathrm{L}$ & 6.25 & 6.11 & 6.03 & 0.168 & 0.28 & 0.25 \\
\hline
\end{tabular}

${ }^{1}$ Control $=0 \mathrm{mg} / \mathrm{d}$ of RPC; C100 $=100 \mathrm{mg} / \mathrm{d}$ of RPC; C200 = $200 \mathrm{mg} / \mathrm{d}$ of RPC.

${ }^{2}$ Highest SEM shown; $\mathrm{n}=108$ for white blood cells and red blood cells; $\mathrm{n}=106$ for all other variables ( $\mathrm{n}$ represents number of observations used in the statistical analysis).

${ }^{3}$ Con vs. RPC $=$ control vs. RPC treatment; Linear $=$ linear effect of RPC. 
Table 3. Effect of rumen-protected Capsicum oleoresin (RPC) on rectal temperature and blood concentration of cortisol, haptoglobin, TBARS, ${ }^{1}$ glucose, and insulin in dairy cows following lipopolysaccharide challenge

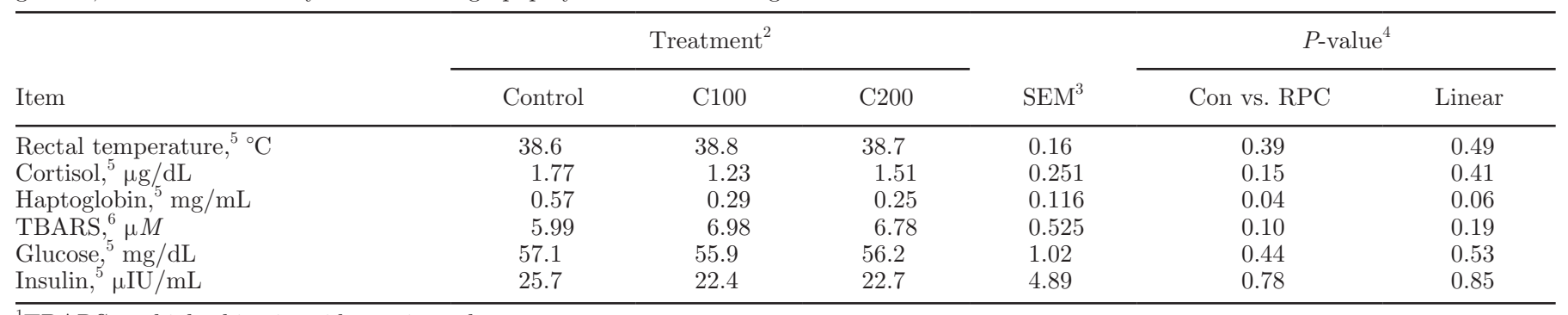

${ }^{1}$ TBARS $=$ thiobarbituric acid reactive substances.

${ }^{2} \mathrm{Control}=0 \mathrm{mg} / \mathrm{d}$ of RPC; $\mathrm{C} 100=100 \mathrm{mg} / \mathrm{d}$ of RPC; $200=200 \mathrm{mg} / \mathrm{d}$ of RPC.

${ }^{3}$ Highest SEM shown; $\mathrm{n}=101$ for rectal temperature, $\mathrm{n}=113$ for glucose, insulin, and haptoglobin; $\mathrm{n}=120$ for cortisol; $\mathrm{n}=109$ for TBARS (n represents number of observations used in the statistical analysis).

${ }^{4}$ Con vs. $\mathrm{RPC}=$ control vs. RPC treatment; Linear $=$ linear effect of RPC.

${ }^{5}$ Time effect, $P<0.01$.

${ }^{6}$ Time effect, $P=0.30$.

following LPS challenge, plasma TBARS concentration was similar among treatments (Table 3 ).

Serum glucose concentration was decreased $(P<$ 0.01 ) by LPS and returned to pre-LPS levels at $24 \mathrm{~h}$ (Figure 5). Blood glucose was not affected by RPC in the current experiment (Table 3). The immune challenge increased $(P<0.01)$ blood insulin concentration, which did not return to the basal levels until $24 \mathrm{~h}$ after the LPS challenge (Figure 5). Overall, insulin concentration was not affected by RPC, although it was

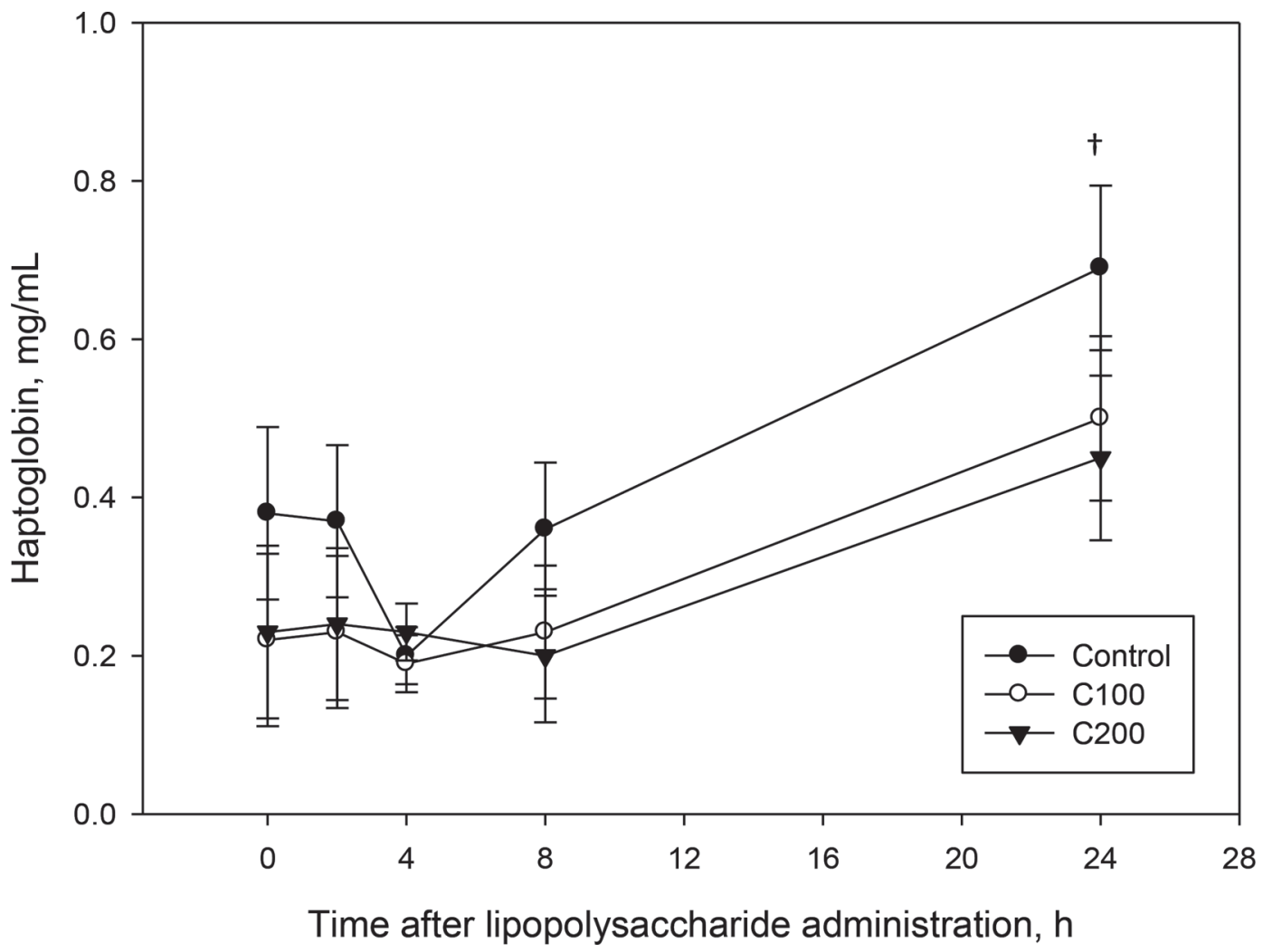

Figure 3. Effect of rumen-protected Capsicum oleoresin (RPC) on serum haptoglobin concentration at $0,2,4,8$, and 24 h after intravenous administration of LPS. Control $=0 \mathrm{mg} / \mathrm{d}$ of RPC; C100 $=100 \mathrm{mg} / \mathrm{d}$ of RPC; C200 $=200 \mathrm{mg} / \mathrm{d}$ of RPC. $\dagger P=0.10$ in control vs. RPC. Time effect, $P<0.01$. Error bars represent SE ( $\mathrm{n}=23$; $\mathrm{n}$ represents number of observations used in the statistical analysis). 
decreased $(P=0.03)$ at $8 \mathrm{~h}$ compared to the control (Table 3).

\section{DISCUSSION}

Decreases in both DMI and milk yield in lactating dairy cows have been consistently shown to be results of LPS challenge (Waldron et al., 2003; Greco et al., 2015; Gott et al., 2015). Pro-inflammatory responses induced by immune challenges are known to decrease appetite during sickness, which may be the reason for the decreased DMI in the current experiment (Kalantar-Zadeh et al., 2004). Milk yield was decreased by LPS as a result of decreased DMI and the increased energy demands of the immune system (Bradford et al., 2015). Decreases in total white blood cells including neutrophils, lymphocytes, monocytes, and eosinophils and increases in rectal temperature, cortisol, and haptoglobin concentrations indicated that intravenous LPS infusion triggered acute phase responses in the cows in the current experiment. Reductions in leukocyte counts due to endotoxin administration were also reported in other studies and are known to be correlated with elevated blood cortisol (Richardson et al., 1989; Wang et al., 2003). The drastic increases in rectal temperature and serum cortisol by LPS and returns to basal levels at $8 \mathrm{~h}$ in the current experiment were consistent with other studies with cattle (Waldron et al., 2003; Waggoner et al., 2009). Serum haptoglobin concentration in the current experiment peaked at $24 \mathrm{~h}$ post LPS challenge, which has been observed in other studies with beef cattle and dairy cows (Waggoner et al., 2009; Greco et al., 2015).

In previous studies with dairy cows we observed that Capsicum had stimulatory effects on immune responses (Oh et al., 2013, 2015). Capsicum oleoresin increased proportions of lymphocytes and $\mathrm{CD} 4^{+} \mathrm{T}$ cells when it was postruminally infused $(2 \mathrm{~g} / \mathrm{d})$ in dairy cows (Oh et al., 2013). Dietary supplementation of Capsicum oleoresin (250 to $1,000 \mathrm{mg} / \mathrm{d}$ ) linearly increased numbers of neutrophils and eosinophils in the study by $\mathrm{Oh}$ et al. (2015). The pro-inflammatory effects of Capsicum in these studies, however, were exhibited in dairy cows without an immune challenge. Capsicum treatment

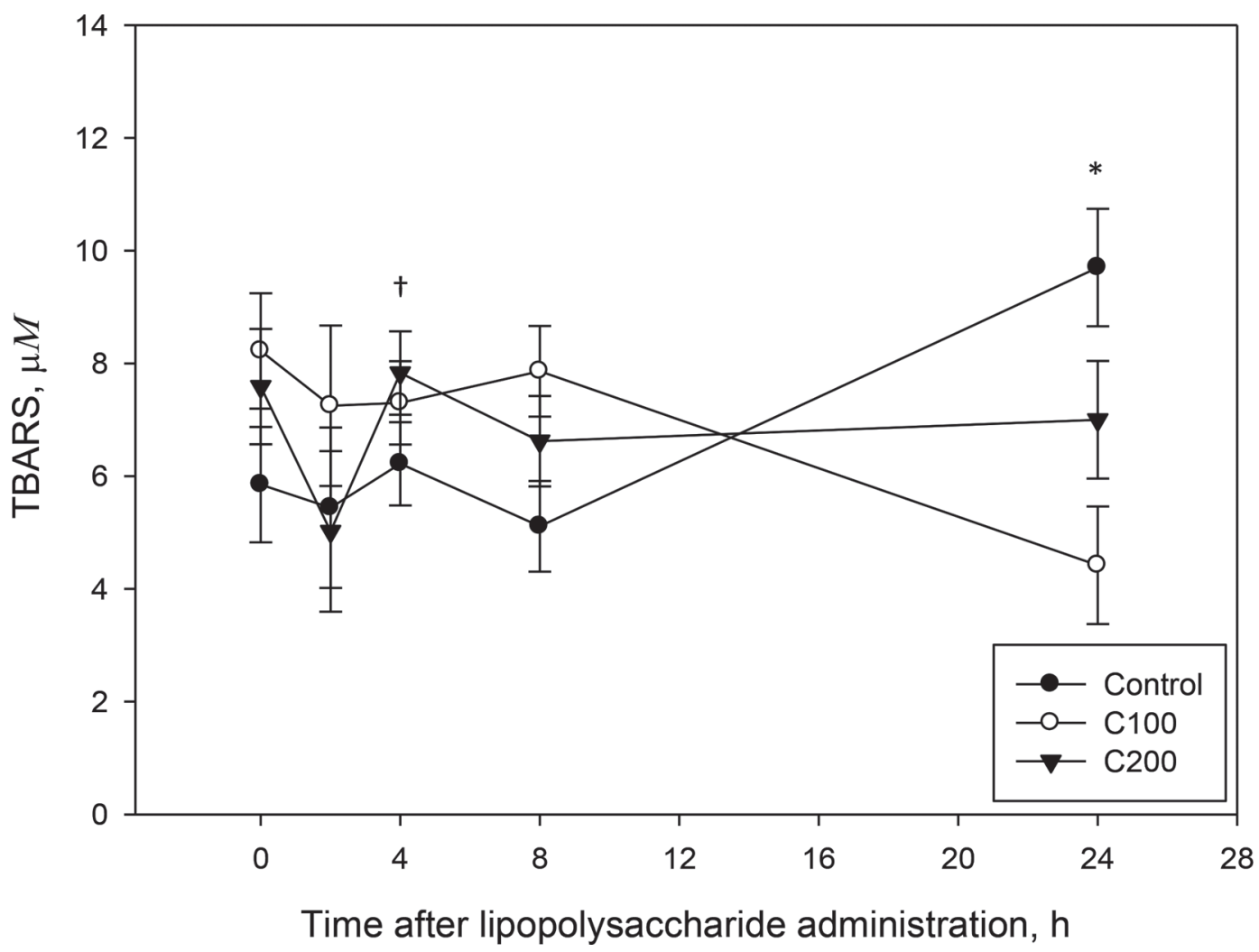

Figure 4. Effect of rumen-protected Capsicum oleoresin (RPC) on the concentration of thiobarbituric acid reactive substances (TBARS) in plasma at $0,2,4,8$, and $24 \mathrm{~h}$ after intravenous administration of LPS. Control $=0 \mathrm{mg} / \mathrm{d}$ of RPC; C100 $=100 \mathrm{mg} / \mathrm{d}$ of RPC; $200=200 \mathrm{mg} / \mathrm{d}$ of RPC. ${ }^{*} P=0.05$ in control vs. RPC; and $\dagger P=0.06$ linear effect of RPC. Time effect, $P=0.30$. Error bars represent $\mathrm{SE}$ (n $=23 ; \mathrm{n}$ represents number of observations used in the statistical analysis). 

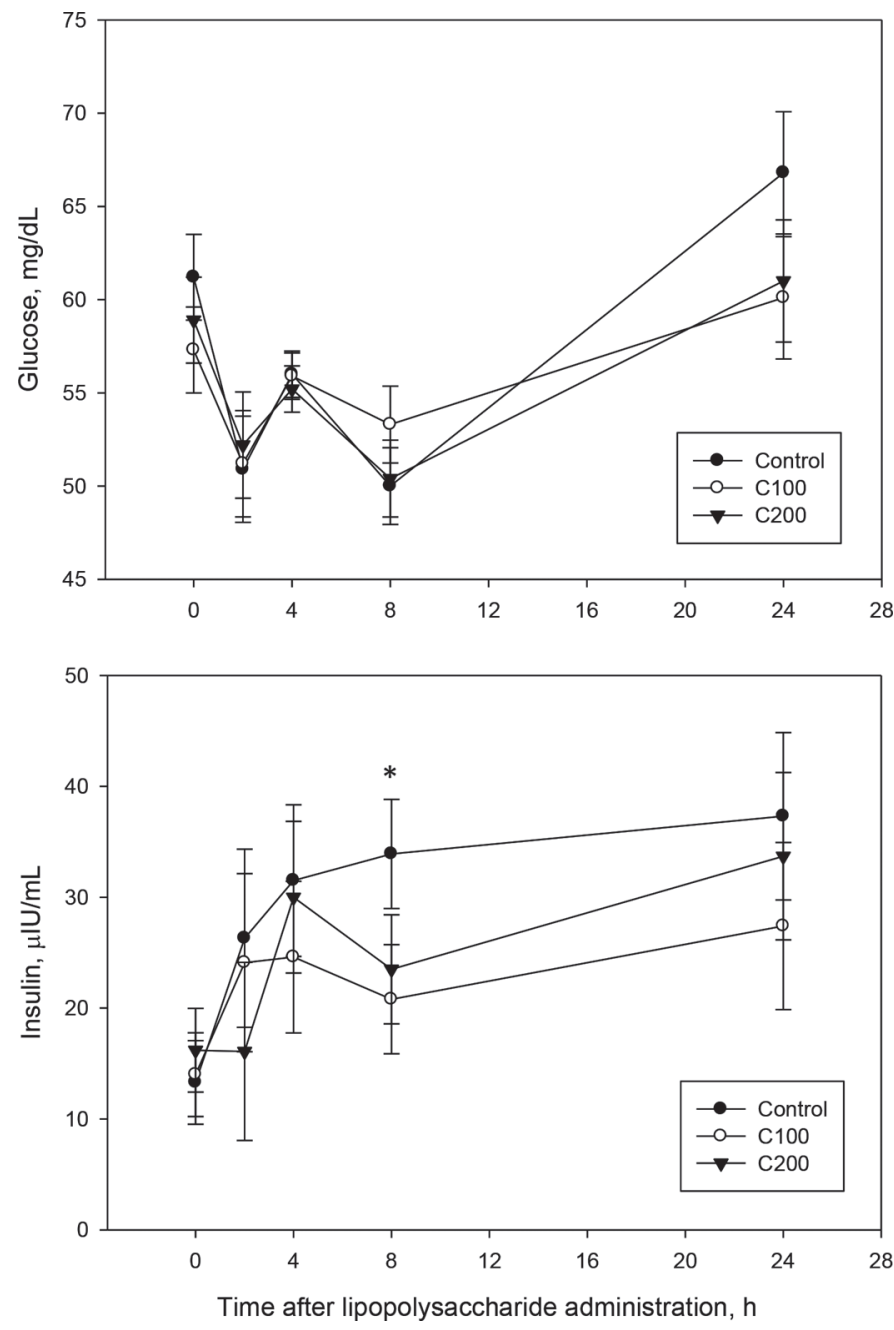

Figure 5. Effect of rumen-protected Capsicum oleoresin (RPC) on serum glucose and insulin concentration at $0,2,4,8$, and $24 \mathrm{~h}$ after intravenous administration of LPS. Control $=0 \mathrm{mg} / \mathrm{d}$ of RPC; C100 $=100 \mathrm{mg} / \mathrm{d}$ of RPC; $200=200 \mathrm{mg} / \mathrm{d}$ of RPC. ${ }^{*} P=0.03$ in control vs. RPC. Time effect, $P<0.01$. Error bars represent SE $(\mathrm{n}=23 ; \mathrm{n}$ represents number of observations used in the statistical analysis).

reportedly exhibited anti-inflammatory effects in pigs challenged with $E$. coli by decreasing pro-inflammatory cytokines (Liu et al., 2013a). In a study using chickens with necrotic enteritis, a mixture of Capsicum and turmeric oleoresins decreased gut lesion scores and mRNA expression of a pro-inflammatory cytokine, LPS-induced tumor necrosis factor (TNF)- $\alpha$, in the jejunum intestinal epithelia (Lee et al., 2013). The regulatory effects of Capsicum on immune cells may depend on the immune status of the animals. Liu et al. (2012) demonstrated in vitro that Capsicum oleoresin exhibited anti-inflammatory effects on porcine macrophages activated with LPS by decreasing concentration of TNF- $\alpha$ produced by the macrophages. With no activation with
LPS, however, Capsicum oleoresin increased TNF- $\alpha$ concentration. We speculated from the previous studies that Capsicum treatment in dairy cows might exhibit anti-inflammatory effects on the acute phase responses induced by LPS.

Results on the effects of Capsicum supplementation on rectal temperature and white blood cells are conflicting among studies. Liu et al. (2013a) supplemented Capsicum oleoresin $(10 \mathrm{mg} / \mathrm{kg} \mathrm{DM})$ in pigs challenged with $E$. coli and observed no effect on rectal temperature and a decrease in white blood cells. In another experiment from the same group, Liu et al. (2013b) reported that Capsicum supplementation $(10 \mathrm{mg} / \mathrm{kg}$ DM) decreased rectal temperature but did not affect white blood cells in pigs challenged with porcine reproductive and respiratory syndrome virus. These studies are consistent with results in the current study.

Trends for decreased blood concentration of cortisol, haptoglobin, and TBARS in the current experiment indicated that RPC may partially alleviate LPS-induced responses in dairy cows. Cortisol, a major stress hormone, is secreted from the adrenal gland, and its secretion is under control of the hypothalamic-pituitaryadrenal axis. Studies on the effects of capsaicin on stress hormones are limited. Choi et al. (2013) observed that repeated oral capsaicin administration increased plasma corticosterone in rats. In a study with pigs, subcutaneous injection of capsaicin increased plasma cortisol levels (Alving et al., 1991). However, rats and pigs were not immune challenged in these studies. In the current experiment, RPC slightly decreased serum cortisol concentration at $2 \mathrm{~h}$ post-LPS challenge. Thus, the effects of capsaicin on cortisol may vary depending on the immune status of the animal. Haptoglobin is an acute phase protein, primarily produced in hepatocytes, that increases during inflammation, tissue damage, and infection (Quaye, 2008). Haptoglobin plays a role in inflammation by scavenging free hemoglobin that damages cellular constituents (Bicho et al., 2013). In addition, haptoglobin induces neutrophil recruitment to sites of inflammation (Quaye, 2008). As in the current study, decreased blood haptoglobin concentration as a result of dietary Capsicum supplementation was reported by Liu et al. (2013a) in pigs challenged with $E$. coli. We observed a lower TBARS concentration with RPC at $24 \mathrm{~h}$ post-LPS challenge, which suggested that lipid peroxidation was decreased at the later stages of LPS challenge. As a marker for oxidative stress, TBARS are byproducts from lipid peroxidation by reactive oxygen species (Moore and Roberts, 1998). Capsaicin has a phenolic group in its molecule, which serves as an antioxidant by scavenging peroxyl radicals (Okada et al., 2010). The TBARS results in the current study 
are consistent with those of Manjunatha and Srinivasan (2006), who reported that capsaicin decreased serum TBARS induced by iron in rats. Capsaicin administered via intragastric and intraperitoneal routes increased concentration of glutathione, an endogenous antioxidant, in the brain, liver, and lung in rats challenged with LPS (Abdel-Salam et al., 2012). In that study, capsaicin administration also decreased serum nitric oxide induced by LPS. Lack of effect of LPS challenge on plasma TBARS was also reported in a poultry study (Star et al., 2008). Although a long-term stress such as heat could increase plasma TBARS, a shortterm exposure to LPS did not affect the oxidative stress status in that experiment (Star et al., 2008). Unlike the current study, LPS challenges resulted in increased oxidative stress in other studies in dairy cows, human subjects, and rats (Bouchard et al., 1999; Dandona et al., 2010; Abdel-Salam et al., 2012).

Decreased acute phase responses with RPC supplementation in the current study did not lead to positive effects on milk production impaired by inflammation and stress following LPS challenge. Studies demonstrated that anti-inflammatory treatments increased milk production in dairy cows (Bertoni et al., 2004; Farney et al., 2013). A mixture of Capsicum and turmeric oleoresins increased BW along with decreased inflammation in chickens (Lee et al., 2013). Milk production data from the current experiment have to be interpreted with caution because of the short duration $(5 \mathrm{~d})$ of the milk yield data collection and the large variability in individual animal responses to LPS; for example, a $3.4 \mathrm{~kg} / \mathrm{d}$ difference in milk yield between the control and C100 did not reach statistical significance.

Hypoglycemia observed post LPS challenge in the current study was also reported for beef cattle, heifers, and dairy cows (McMahon et al., 1998; Steiger et al., 1999; Waldron et al., 2003; Vernay et al., 2012). In those studies, blood glucose concentrations initially increased at $2 \mathrm{~h}$ or less and thereafter decreased below the glucose levels of pre-LPS challenge. This pattern could not be confirmed in the current experiment because blood samples were not taken between 0 and 2 $\mathrm{h}$ post-LPS challenge. The initial increases of glucose concentration in those studies were likely due to enhanced glycogenolysis in the liver (McGuinness, 2005). Hypoglycemia following the initial glucose responses represents depletion of glycogen stores due to energy demands of the immune system and the lack of gluconeogenesis (McGuinness, 2005). Insulin is also a suppressor of gluconeogenesis because it inhibits expression of glucose 6-phosphatase, an enzyme involved in the last step of gluconeogenesis (van Schaftingen and Gerin, 2002; De Koster and Opsomer, 2013). In the current experiment, we observed hypoglycemia with increased insulin concentration following LPS challenge. Capsaicin reportedly reduced insulin secretion in rats and human subjects (van de Wall et al., 2005; Ahuja et al., 2006). In our companion study, we observed decreases in serum insulin concentration with RPC during a glucose tolerance test (Oh et al., 2017). With LPS challenge in the current study, however, RPC did not affect insulin and had no effect on glucose concentration, which suggests that RPC does not ameliorate hypoglycemia caused by LPS.

\section{CONCLUSIONS}

Dietary supplementation of RPC had no or subtle effects on feed intake, milk yield, rectal temperature, white and red blood cells, and serum glucose and insulin concentration in dairy cows challenged with LPS. However, RPC tended to decrease cortisol and decreased haptoglobin and TBARS concentrations in blood. Data suggest that RPC fed at 100 to $200 \mathrm{mg} / \mathrm{d}$ may modulate acute phase responses induced by bacterial infection in lactating dairy cows.

\section{ACKNOWLEDGMENTS}

The authors thank Pancosma S.A. (Geneva, Switzerland) for providing partial financial support for this project and the RPC used in the experiment, Centralized Biological Laboratory for the hematology analyses, The Pennsylvania State University's Metabolomics Core Facility for capsaicin analysis in milk, The Pennsylvania State University's Animal Diagnostic Laboratory for providing Streptococcus uberis, and the staffs of the Pennsylvania State University's Dairy Teaching and Research Center for their conscientious care of the experimental cows.

\section{REFERENCES}

Abdel-Salam, O. M., R. F. Abdel-Rahman, A. A. Sleem, and A. R. Farrag. 2012. Modulation of lipopolysaccharide-induced oxidative stress by capsaicin. Inflammopharmacology 20:207-217.

Ahuja, K. D., I. K. Robertson, D. P. Geraghty, and M. J. Ball. 2006 Effects of chili consumption on postprandial glucose, insulin, and energy metabolism. Am. J. Clin. Nutr. 84:63-69.

Alving, K., R. Matran, and J. M. Lundberg. 1991. Capsaicin-induced local effector responses, autonomic reflexes and sensory neuropeptide depletion in the pig. Naunyn Schmiedebergs Arch. Pharmacol. 343:37-45.

Bender, A. M., and R. D. Granstein. 2009. Modulation of immune cells by products of nerves. Pages 45-53 in Neuroimmunology of the Skin: Basic Science to Clinical Practice. R. D. Granstein and T. A. Luger, ed. Springer-Verlag, Berlin, Germany.

Bertoni, G., E. Trevisi, and F. Piccioli-Cappelli. 2004. Effects of acetyl-salicylate used in post-calving of dairy cows. Vet. Res. Commun. 28:217-219. 
Bicho, M. C., A. P. Silva, R. Medeiros, and M. Bicho. 2013. The role of haptoglobin and its genetic polymorphism in cancer: A review. Pages 55-76 in Acute Phase Protein. S. Janciauskiene, ed. InTech, Rijeka, Croatia.

Bouchard, L., S. Blais, C. Desrosiers, X. Zhao, and P. Lacasse. 1999 Nitric oxide production during endotoxin-induced mastitis in the cow. J. Dairy Sci. 82:2574-2581.

Bradford, B. J., K. Yuan, J. K. Farney, L. K. Mamedova, and A. J. Carpenter. 2015. Invited review: Inflammation during the transition to lactation: New adventures with an old flame. J. Dairy Sci. 98:6631-6650.

Choi, Y. J., J. Y. Kim, S. B. Yoo, J. H. Lee, and J. W. Jahng. 2013. Repeated oral administration of capsaicin increases anxiety-like behaviours with prolonged stress-response in rats. J. Biosci. 38:561-571.

Cortright, D. N., and A. Szallasi. 2004. Biochemical pharmacology of the vanilloid receptor TRPV1. Eur. J. Biochem. 271:1814-1819.

Cray, C., J. Zaias, and N. H. Altman. 2009. Acute phase response in animals: A review. Comp. Med. 59:517-526.

Dandona, P., H. Ghanim, A. Bandyopadhyay, K. Korzeniewski, C. Ling Sia, S. Dhindsa, and A. Chaudhuri. 2010. Insulin suppresses endotoxin-induced oxidative, nitrosative, and inflammatory stress in humans. Diabetes Care 33:2416-2423.

De Koster, J. D., and G. Opsomer. 2013. Insulin resistance in dairy cows. Vet. Clin. North Am. Food Anim. Pract. 29:299-322.

Farney, J. K., L. K. Mamedova, J. F. Coetzee, B. KuKanich, L. M. Sordillo, S. K. Stoakes, J. E. Minton, L. C. Hollis, and B. J. Bradford. 2013. Anti-inflammatory salicylate treatment alters the metabolic adaptations to lactation in dairy cattle. Am. J. Physiol. Regul. Integr. Comp. Physiol. 305:R110-R117.

Franco-Penteado, C. F., I. A. De Souza, C. S. Lima, S. A. Teixeira, M. N. Muscara, G. De Nucci, and E. Antunes. 2006. Effects of neonatal capsaicin treatment in the neutrophil production, and expression of preprotachykinin-I and tachykinin receptors in the rat bone marrow. Neurosci. Lett. 407:70-73.

Gott, P. N., J. S. Hogan, and W. P. Weiss. 2015. Effects of various starch feeding regimens on responses of dairy cows to intramammary lipopolysaccharide infusion. J. Dairy Sci. 98:1786-1796.

Greco, L. F., J. T. N. Neto, A. Pedrico, R. A. Ferrazza, F. S. Lima, R S. Bisinotto, N. Martinez, M. Garcia, E. S. Ribeiro, G. C. Gomes, J. H. Shin, M. A. Ballou, W. W. Thatcher, C. R. Staples, and J. E. P. Santos. 2015. Effects of altering the ratio of dietary n- 6 to n-3 fatty acids on performance and inflammatory responses to a lipopolysaccharide challenge in lactating Holstein cows. J. Dairy Sci. 98:602-617.

Gruys, E., M. J. Toussaint, T. A. Niewold, and S. J. Koopmans. 2005. Acute phase reaction and acute phase proteins. J. Zhejiang Univ. Sci. B 6:1045-1056.

Hoebe, K., E. Janssen, and B. Beutler. 2004. The interface between innate and adaptive immunity. Nat. Immunol. 5:971-974.

Kalantar-Zadeh, K., G. Block, C. J. McAllister, M. H. Humphreys, and J. D. Kopple. 2004. Appetite and inflammation, nutrition, anemia, and clinical outcome in hemodialysis patients. Am. J. Clin. Nutr. 80:299-307.

Kramer, J. W. 2000. Normal hematology of cattle, sheep, and goats. Pages 1075-1084 in Schalm's Veterinary Hematology. B. Feldman, J. Zinkl, and N. Jain, ed. Lippincott, Philadelphia, PA.

Lee, S. H., H. S. Lillehoj, S. I. Jang, E. P. Lillehoj, W. Min, and D. M. Bravo. 2013. Dietary supplementation of young broiler chickens with Capsicum and turmeric oleoresins increases resistance to necrotic enteritis. Br. J. Nutr. 110:840-847.

Liu, Y., T. M. Che, M. Song, J. J. Lee, J. A. Almeida, D. Bravo, W. G. Van Alstine, and J. E. Pettigrew. 2013b. Dietary plant extracts improve immune responses and growth efficiency of pigs experimentally infected with porcine reproductive and respiratory syndrome virus. J. Anim. Sci. 91:5668-5679.

Liu, Y., M. Song, T. M. Che, J. A. Almeida, J. J. Lee, D. Bravo, C W. Maddox, and J. E. Pettigrew. 2013a. Dietary plant extracts alleviate diarrhea and alter immune responses of weaned pigs experimentally infected with a pathogenic Escherichia coli. J. Anim. Sci. 91:5294-5306.
Liu, Y., M. Song, T. M. Che, D. Bravo, C. W. Maddox, and J. E. Pettigrew. 2014. Effects of capsicum oleoresin, garlic botanical, and turmeric oleoresin on gene expression profile of ileal mucosa in weaned pigs. J. Anim. Sci. 92:3426-3440.

Liu, Y., M. Song, T. M. Che, D. Bravo, and J. E. Pettigrew. 2012. Anti-inflammatory effects of several plant extracts on porcine alveolar macrophages in vitro. J. Anim. Sci. 90:2774-2783.

Manjunatha, H., and K. Srinivasan. 2006. Protective effect of dietary curcumin and capsaicin on induced oxidation of low-density lipoprotein, iron-induced hepatotoxicity and carrageenan-induced inflammation in experimental rats. FEBS J. 273:4528-4537.

McGuinness, O. P. 2005. Defective glucose homeostasis during infection. Annu. Rev. Nutr. 25:9-35.

McMahon, C. D., T. H. Elsasser, D. R. Gunter, L. G. Sanders, B. P. Steele, and J. L. Sartin. 1998. Estradiol/progesterone implants increase food intake, reduce hyperglycemia and increase insulin resistance in endotoxic steers. J. Endocrinol. 159:469-478.

Moore, K., and L. J. Roberts. 1998. Measurement of lipid peroxidation. Free Radic. Res. 28:659-671.

Nevius, E., P. K. Srivastava, and S. Basu. 2012. Oral ingestion of Capsaicin, the pungent component of chili pepper, enhances a discreet population of macrophages and confers protection from autoimmune diabetes. Mucosal Immunol. 5:76-86.

Nilsson, G., K. Alving, and S. Ahlstedt. 1991. Effects on immune responses in rats after neuromanipulation with capsaicin. Int. J. Immunopharmacol. 13:21-26.

NRC. 2001. Nutrient Requirements of Dairy Cattle. 7th rev. ed. Natl. Acad. Sci., Washington, DC.

Oh, J., M. Harper, F. Giallongo, D. M. Bravo, E. H. Wall, and A. N. Hristov. 2017. Effects of rumen-protected Capsicum oleoresin on productivity and responses to a glucose tolerance test in lactating dairy cows. J. Dairy Sci. 100:1888-1901. https://doi.org/10.3168/ jds.2016-11665.

Oh, J., A. N. Hristov, F. Giallongo, T. Frederick, J. Pate, S. Walusimbi, R. J. Elias, E. H. Wall, and D. Bravo. 2015. Effects of dietary Capsicum oleoresin on productivity and immune responses in lactating dairy cows. J. Dairy Sci. 98:6327-6339.

Oh, J., A. N. Hristov, C. Lee, T. Cassidy, K. Heyler, G. A. Varga, J. Pate, S. Walusimbi, E. Brzezicka, K. Toyokawa, J. Werner, S. S. Donkin, R. Elias, S. Dowd, and D. Bravo. 2013. Immune and production responses of dairy cows to postruminal supplementation with phytonutrients. J. Dairy Sci. 96:7830-7843

Okada, Y.. K. Tanaka, E. Sato, and H. Okajima. 2010. Kinetics and antioxidative sites of capsaicin in homogeneous solution. J. Am. Oil Chem. Soc. 87:1397-1405.

Quaye, I. K. 2008. Haptoglobin, inflammation and disease. Trans. R. Soc. Trop. Med. Hyg. 102:735-742.

Reyes-Escogido, M. L., E. G. Gonzalez-Mondragon, and E. VazquezTzompantzi. 2011. Chemical and pharmacological aspects of capsaicin. Molecules 16:1253-1270.

Richardson, R. P., C. D. Rhyne, Y. Fong, D. G. Hesse, K. J. Tracey, M. A. Marano, S. F. Lowry, A. C. Antonacci, and S. E. Calvano. 1989 Peripheral blood leukocyte kinetics following in vivo lipopolysaccharide (LPS) administration to normal human subjects. Influence of elicited hormones and cytokines. Ann. Surg. 210:239-245.

Sjaunja, L. O., L. Baevre, L. Junkkarinen, J. Pedersen, and J. Setälä. 1990. A Nordic proposal for an energy corrected milk (ECM) formula. In 27th Session of the International Commission for Breeding and Productivity of Milk Animals, Paris, France. Wageningen Academic Publishers, Wageningen, the Netherlands.

Sordillo, L. M., and S. L. Aitken. 2009. Impact of oxidative stress on the health and immune function of dairy cattle. Vet. Immunol. Immunopathol. 128:104-109.

Star, L., E. Decuypere, H. K. Parmentier, and B. Kemp. 2008. Effect of single or combined climatic and hygienic stress in four layer lines: 2. Endocrine and oxidative stress responses. Poult. Sci. $87: 1031-1038$

Steiger, M., M. Senn, G. Altreuther, D. Werling, F. Sutter, M. Kreuzer, and W. Langhans. 1999. Effect of a prolonged low-dose lipopolysaccharide infusion on feed intake and metabolism in heifers. J. Anim. Sci. 77:2523-2532. 
Takano, F., M. Yamaguchi, S. Takada, S. Shoda, N. Yahagi, T. Takahashi, and T. Ohta. 2007. Capsicum ethanol extracts and capsaicin enhance interleukin-2 and interferon-gamma production in cultured murine Peyer's patch cells ex vivo. Life Sci. 80:1553-1563.

Tsuji, F., and H. Aono. 2012. Role of transient receptor potential vanilloid 1 in inflammation and autoimmune diseases. Pharmaceuticals (Basel) 5:837-852.

van de Wall, E. H., D. X. Gram, J. H. Strubbe, A. J. Scheurink, and J. M. Koolhaas. 2005. Ablation of capsaicin-sensitive afferent nerves affects insulin response during an intravenous glucose tolerance test. Life Sci. 77:1283-1292.

van Schaftingen, E., and I. Gerin. 2002. The glucose-6-phosphatase system. Biochem. J. 362:513-532.

Vernay, M. C. M. B., O. Wellnitz, L. Kreipe, H. A. van Dorland, and R. M. Bruckmaier. 2012. Local and systemic response to intramammary lipopolysaccharide challenge during long-term manipulated plasma glucose and insulin concentrations in dairy cows. J. Dairy Sci. 95:2540-2549.
Waggoner, J. W., C. A. Löest, J. L. Turner, C. P. Mathis, and D. M. Hallford. 2009. Effects of dietary protein and bacterial lipopolysaccharide infusion on nitrogen metabolism and hormonal responses of growing beef steers. J. Anim. Sci. 87:3656-3668.

Waldron, M. R., T. Nishida, B. J. Nonneche, and T. R. Overton. 2003. Effect of lipopolysaccharide on indices of peripheral and hepatic metabolism in lactating cows. J. Dairy Sci. 86:3447-3459.

Wang, W., R. F. Wideman Jr., M. E. Chapman, T. K. Bersi, and G. F. Erf. 2003. Effect of intravenous endotoxin on blood cell profiles of broilers housed in cages and floor litter environments. Poult. Sci. 82:1886-1897.

Wesolowska, A., D. Jadczak, and M. Grzeszczuk. 2011. Chemical composition of the pepper fruit extracts of hot cultivars Capsicum annuum L. Acta Scientiarum Polonorum Hortorum Cultus 10:171-184. 